\title{
Two Molecular Markers of Early Non-Small Cell Lung Carcinoma Based on Gene Expression in Peripheral Blood
}

\author{
Naghmeh Bahrami ${ }^{1,2}$, Hamidreza Jamaati ${ }^{3}$, Jalal Heshmat Nia ${ }^{3}$, Payam Tabarsi ${ }^{4}$, \\ Atefeh Fakharian ${ }^{3}$, Habib Emami' ${ }^{5}$, Somayeh Sharifynia4, Masoum Abniki6, \\ Abdolreza Mohamadnia ${ }^{7,8^{*}}$ \\ ${ }^{1}$ Craniomaxillofacial Research center, Tehran University of Medical Sciences, Tehran, Iran \\ ${ }^{2}$ Oral and Maxillofacial Surgery Department, School of Dentistry, Tehran University of Medical Sciences, Tehran, Iran \\ ${ }^{3}$ Chronic Respiratory Diseases Research Center, National Research Institute of Tuberculosis and Lung Diseases (NRITLD), Shahid \\ Beheshti University of Medical Sciences, Tehran, Iran \\ ${ }^{4}$ Clinical Tuberculosis and Epidemiology Research Center, National Research Institute of Tuberculosis and Lung Diseases \\ (NRITLD), Shahid Beheshti University of Medical Sciences, Tehran, Iran \\ ${ }^{5}$ Tobacco prevention and control research center, National Research Institute of Tuberculosis and Lung Diseases (NRITLD), \\ Shahid Beheshti University of Medical Sciences, Tehran, Iran \\ ${ }^{6}$ Department of Biotechnology, Faculty of Sciences, Islamic Azad University, Tehran, Iran \\ ${ }^{7}$ Virology Research Center, National Research Institute of Tuberculosis and Lung Diseases (NRITLD), Shahid Beheshti University \\ of Medical Sciences, Tehran, Iran \\ ${ }^{8}$ Department of Biotechnology, School of Advanced Technologies in Medicine, Shahid Beheshti University of Medical Sciences, \\ Tehran, Iran \\ Email: *mohamadnia.ar@gmail.com
}

How to cite this paper: Bahrami, N., Jamaati, H., Nia, J.H., Tabarsi, P., Fakharian, A., Emami, H., Sharifynia, S., Abniki, M. and Mohamadnia, A. (2017) Two Molecular Markers of Early Non-Small Cell Lung Carcinoma Based on Gene Expression in Peripheral Blood. Open Journal of Clinical Diagnostics, 7, 91-102.

https://doi.org/10.4236/ojcd.2017.73010

Received: July 10, 2017

Accepted: August 11, 2017

Published: August 14, 2017

Copyright $\odot 2017$ by authors and Scientific Research Publishing Inc. This work is licensed under the Creative Commons Attribution International License (CC BY 4.0).

\begin{abstract}
Background: Lung cancer is among the most common cancers. Search is ongoing to find biomarkers to improve the diagnosis lung cancer techniques in early stages. In this study we evaluate the sensitivity and specificity of the MUC1 and CEA gene expressions in the peripheral blood of non-small cell lung cancer (NSCLC). Material and Methods: This study was done in Masih Daneshvari Hospital, Tehran, Iran and was case/control study that conducted on 30 NSCLC patients and 30 healthy controls. Peripheral blood was collected and total RNA was extracted then cDNA was synthesized. Sample was separately assessed by real time PCR. Results: The expression of CEA gen was positive in 24 patients indicating $80 \%$ sensitivity for this marker. The expression of CEA gen was positive in 9 controls out of 30 each. A statistically significant difference was detected between patients and healthy controls with regard to CEA mRNA expression $(\mathrm{P}<0.001)$. The MUC1 gen expressed in 20 out of 30 patients, while it expressed in 3 controls. The difference in MUC1 mRNA expression was statistically significant between NSCLC patients and
\end{abstract}


http://creativecommons.org/licenses/by/4.0/ Open Access healthy controls $(\mathrm{P}<0.001)$. Conclusion: MUC1 and CEA are molecular biomarkers with relatively favorable sensitivity for primary diagnosis of NSCLC.

\section{Keywords}

MUC1 mRNA, CEA mRNA, Non-Small Cell Lung Cancer, Biomarker

\section{Introduction}

Lung cancer is among the most common cancers worldwide and over $80 \%$ of the lung cancer patients have an approximately 5-year survival rate after diagnosis [1]. Lung cancer is categorized into two types of NSCLC and small cell lung cancer (SCLC). NSCLC is an epithelial tumor with a high invasive clinical stage. It has high rate of metastasis in early stages [2] [3]. In the past couple of decades, there was less attention to the therapeutic approaches for lung cancer [2]. Incidence of lung cancer is variable in different races and ethnic groups and it is the first cause of morbidity and mortality in the United States [3]. The overall risk of developing lung cancer is $8 \%$ for men and $6 \%$ for women [3].

The occurrence of lung cancer is the result of tumoral growth and uncontrolled proliferation of pulmonary cells. Exposure to environmental carcinogens such as cigarette smoke causes dysplastic changes in bronchial epithelial cells and leads to neoplastic changes and malignancy. Moreover, some genetic factors predispose patients to malignant phenotypes [4]. Tumoral biomarkers are protein or glycoprotein molecules produced in response to presence or progression of cancer, which are found in body fluids and cancerous tissue [4] [5] [6]. To date, no tumoral biomarker has been identified for efficient prediction of patient prognosis. However, some markers are useful for diagnosis or prediction of tumor, determining the presence of metastasis or for selection and timing of therapeutic regimens [7]. Using affordable and non-invasive tumor biomarkers ease the pathway to cancer diagnosis [8] [9] [10] [11].

The CEA is a set of glycoproteins produced in the liver during fetal development and its production ceases before birth. This marker is used for assessment of many types of cancer such as lung and pancreatic cancer. The tumor growth factor beta (TGF-B) mediates cell adhesion to extra-cellular matrix and regulates the expression of CEA. The CEA factor increases in lung cancer. Therefore, the expression of CEA increases, leading to consequent metastasis of cancer cells [12] [13] [14]. Expression of CEA decreases after the treatment starts and it indicates a positive response to treatment and growth inhibition of tumoral cells [15]. In previous studies, the sensitivity of CEA biomarker in lung cancer was higher than in other malignancies [16] [17].

The MUC1 is a mucin encoded by MUC1 gene in humans; it is a glycoprotein with extensive O-linked glycosylation of its extracellular domain [18]. Mucin lines the apical surface of the lungs, stomach, intestines, eyes and some other organs [19] protects the body from infections caused by the pathogens attached 
to extracellular domains and prevents the access of pathogens to the cell surface [20]. High expression of MUC1 gene is often associated with colon, breast, ovarian, lung and pancreatic cancers [21]. The MUC1 membrane bound, glycosylated phosphoprotein is a member of the mucin family [22] and has a $120-225$ KD central protein; its molecular weight can increase to 350 - $500 \mathrm{KD}$ by glycosylation; in the latter case, it extends to the other side of the cell surface by 200 $500 \mathrm{~nm}$ [23] [24]. Based on all the above, assessment of CEA mRNA and MUC1 mRNA expressionas tumoral biomarkers in the peripheral blood using RT-PCR may be useful in lung cancer patients.

The 18 S subunit of ribosomal RNA (18SrRNA) is encoded by 18SrRNA housekeeping gene; the level of expression of this gene as a reference gene can be assessed by RT-PCR [25] [26] [27].

In this study, we investigate the level of expression of CEA mRNA and MUC1 mRNA by real-time RT-PCR in the peripheral blood of patients with NSCLC. Also, we assess the sensitivity and specificity of the afore-mentioned two biomarkers for early detection and diagnosis of NSCLC for prompt treatment before metastasis.

\section{Materials and Methods}

\subsection{Study Groups}

In this case/control study, was conducted on two groups; first, the NSCLC patients (pathologically confirmed stages 1 to 3 ) comprised the test group of our study. After obtaining ethical code to No.sbmu1.REC.1394.115, They were selected among patients presenting to Masih Daneshvari Hospital affiliated to Shahid Beheshti University of Medical Sciences, Tehran, Iran since 2015-2016. Those with no history of chemotherapy or surgery were chosen and blood samples were drawn prior to initiation of treatment. Second, healthy control group that were selected among subjects presenting to the same hospital with normal bronchoscopic or pathologic findings. The control subjects were matched with the patients in terms of age and sex.

\subsection{Sample Collection}

The objectives of the study were thoroughly explained to both test and control subjects and written informed consent was obtained from them. Subjects were requested to fill out a questionnaire asking for their demographics and disease status. Next, $10 \mathrm{~mL}$ of peripheral blood was drawn. The first $2 \mathrm{~mL}$ was discarded due to the risk of contamination with epithelial cells; the remaining $8 \mathrm{~mL}$ was transferred to a Falcon tube containing ethylenediaminetetraacetic acid (EDTA) anticoagulant and sent to a laboratory for RNA extraction.

\subsection{Red Blood Cell Lysis}

As stated earlier, $8 \mathrm{~mL}$ of blood was used for RNA extraction. To lyse the RBCs, $32 \mathrm{~mL}$ of the RBC lysis buffer (four times the blood sample volume) was added 
to $8 \mathrm{~mL}$ of blood and the mixture was incubated for 30 minutes; the solution was vortexed for several times during this time period. The solution-containing vial was then centrifuged at $4000 \times \mathrm{g}$ for 20 minutes; the supernatant was discarded and $8 \mathrm{~mL}$ of the lysis solution was added to the sediment and centrifuged at 3000 $\times \mathrm{g}$ for 10 minutes. The supernatant was discarded and the sediment containing white blood cells and tumoral cells was used for RNA extraction.

\subsection{RNA Extraction}

RNeasy Midi Kit (Qiagen Cat No. 75144) was used for RNA extraction. The sediment obtained in the previous step was first lysed using RLT lysing solution present in the lysis kit. Next, $70 \%$ ethanol was added and the solution was poured on the extraction column and centrifuged at $3000 \mathrm{~g}$ for 5 minutes. In the next step, RW1 and PRE solutions present in the kit were added to the column, respectively and centrifuged to eliminate the DNA, proteins and other impurities. The pure RNA was then extracted from the column using $250 \mu \mathrm{L}$ of RNAsefree water. The quality and quantity of the extracted RNA were controlled by NanoDrop ${ }^{\circ}$. Based on the concentration of extracted RNA and maximum capacity of cDNA synthesis, $15 \mu \mathrm{L}$ of each RNA vial was immediately used for cDNA synthesis.

\subsection{Reverse Transcription}

For reverse transcription, $15 \mu \mathrm{L}$ of RNA was reverse transcribed to cDNA using Viva 2-step RT-PCR kit (Cat No. RTPL12). This process was repeated three times and three vials of cDNA were synthesized. Final testing was performed on each vial of each sample. The purity and quantity of cDNA were measured by NanoDrop ${ }^{\oplus}$. The quality of cDNA for real-time RT-PCR was confirmed by observation of $18 \mathrm{SrRNA}$ expression in each sample.

\subsection{Primers}

Specific primers for each marker were designed using AlleleID7 software and ordered for synthesis. The sequence of primers and their amount used in the final reaction of real-time RT-PCR are presented in Table 1.

\subsection{Real-Time qRT-PCR}

To assess the presence of Muc1 mRNA and CEA mRNA, cDNA vials were tested by real-time RT-PCR using HotTaqEvaGreenqPCRMix kit. The real-time RTPCR reaction components included (A) $2 \mu \mathrm{L}$ of the template, (B) $4 \mu \mathrm{L}$ of the Master mix, (C) Primer with optimal concentration found in set up tests, (D) Deionized distilled water to reach a final reaction volume of $20 \mu \mathrm{L}$. Positive and negative controls were also used simultaneously for quality control and detection of possible contamination.

\subsection{Statistical Analysis}

Sample size was calculated taking into account the ratio of positivity for the 
Table 1. Characteristics of the primers used in real-time RT-PCR. Number of each gene and sequence, length and amount of each primer are also demonstrated.

\begin{tabular}{cccc}
\hline Characteristics & CEA & MUC1 & 18s rRNA \\
\hline $\begin{array}{c}\text { NCBI accession } \\
\text { number }\end{array}$ & M29540 & NM_002456 & X03205 \\
Forward primer & accctggatgtcctctatgg & GTGCCCCCTAGCAGTACCG & gtaacccgttgaaccccatt \\
Primer length & 20 & 19 & 20 \\
Amount of use & 10 picomol & 10 picomol & 10 picomol \\
Reverse primer & caggcataggtcccgttatta GACGTGCCCCTACAAGTTGG ccatccaatcggtagtagcg \\
Primer length & 21 & 20 & 20 \\
Amount of use & 10 picomol & 10 picomol & 10 picomol \\
Amplicon length & 174 & 123 & 152 \\
Optimized annealing & $61.4^{\circ} \mathrm{C}$ & $61.6^{\circ} \mathrm{C}$ & $53.6^{\circ} \mathrm{C}$ \\
temperature & & & \\
\hline
\end{tabular}

markers in the two groups based on primary estimates in similar previous studies [24] as well as using sample size estimation formula considering type one error of $5 \%$ and type two error of $20 \%$. The data were analyzed using SPSS version 22. The mean values were compared between the two groups of test and control using t-test. Gene expression ratios in the two groups were statistically analyzed and compared using Chi square test. Level of significance was set at $\mathrm{P} \leq 0.05$.

\section{Results}

A total of 30 NSCLC patients and 30 healthy controls were evaluated. Of 30 patients, 24 were males and 6 were females. No statistically significant difference was noted between males and females in this regard either $(\mathrm{P}=0.475)$.

Comparison of the mean age showed difference between patients and controls is not statistically significant (Table 2).

\subsection{Expression of 18SrRNA Reference Gene}

The threshold cycle $(\mathrm{Ct})$ value of $18 \mathrm{SrRNA}$ reference gene determined by PCR was reported for each sample. The mean Ct value was 18.83 in the group of patients and 17.27 in the group of healthy individuals; comparison of the mean $\mathrm{Ct}$ values revealed no statistically significant difference between the two groups $(\mathrm{P}=$ 0.102) and indicated that the selection of this biomarker as the reference gene was appropriate.

\subsection{Analysis of the Expression of MUC1 mRNA and CEA mRNA}

In the group of patients, 24 out of 30 were positive for CEA mRNA expression. Thus, the sensitivity of this biomarker was $80 \%$. Of the healthy individuals, 9 out of 30 were positive for CEA mRNA, indicating $30 \%$ false positive results.

There was a statistically significant difference between the positive expression 
of CEA mRNA biomarker in patients and healthy controls $(\mathrm{P}<0.001)$. In the NSCLC group, 20 out of 30 were positive for MUC1 mRNA expression, indicating $66.6 \%$ sensitivity. Among healthy controls, 3 out of 30 were positive for MUC1 mRNA expression. The difference in this regard between patients and healthy controls was statistically significant $(\mathrm{P}<0.001)$ (Figure 1$)$.

The technique used in this study was based on increasing the number of vials; in other words, the tests were performed in triplicate. To find out whether this method increased sensitivity, the level of positivity of vials 1, 2 and 3 and the level of positivity of each marker in general were assessed and significant differences were noted with regard to the positivity of each vial and general positivity for the CEA mRNA marker. Also, comparison of level of positivity of vials 1, 2 and 3 with general positivity for the expression of MUC1 mRNA biomarker revealed a significant difference (Table 3 ).

Table 2. Comparison of the age between patients and controls.

\begin{tabular}{cccc}
\hline & Group & Mean & P-Value \\
\hline Age & Patient & $51 \pm 11.16$ & $\mathrm{P}=0.096$ \\
& Normal & $46.40 \pm 9.84$ & \\
\hline
\end{tabular}

Table 3. Comparison of level of positivity of vials 1, 2 and 3 with general level of positivity and comparison of sensitivity values with two-sample binomial test in the NSCLC patients.

\begin{tabular}{|c|c|c|c|c|c|c|}
\hline \multirow{2}{*}{ Vial } & \multicolumn{3}{|c|}{ CEA mRNA } & \multicolumn{3}{|c|}{ MUC1 mRNA } \\
\hline & Positive rate (\%) & Sensitivity (\%) & $P$ value & Positive rate (\%) & Sensitivity (\%) & $P$ value \\
\hline 1 & 60 & & 0.001 & 56 & & $<0.001$ \\
\hline 2 & 70 & 80 & $<0.001$ & 46 & 66.6 & $<0.001$ \\
\hline 3 & 60 & & $<0.001$ & 50 & & 0.001 \\
\hline
\end{tabular}

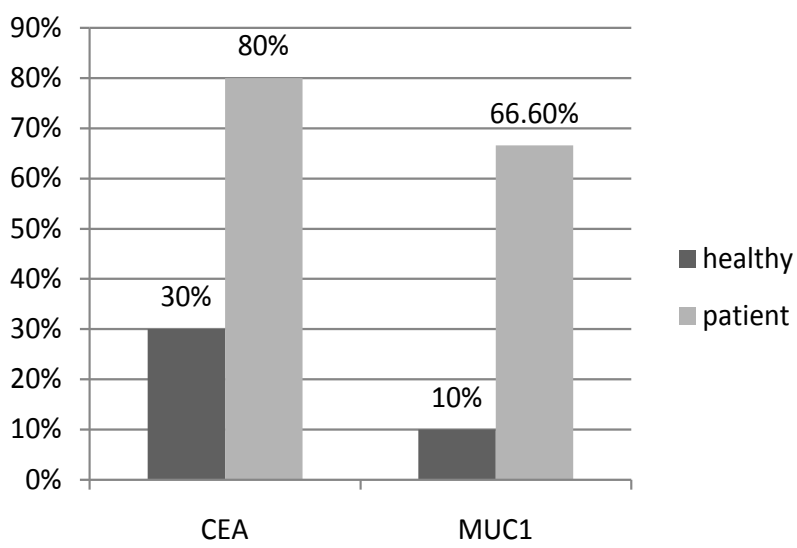

Figure 1. The expression levels of MUC1 mRNA and CEA mRNA in peripheral blood from NSCLC patients and healthy group. 


\subsection{Difference in Expression of Biomarkers between the Two Groups of Patients and Controls}

To make a comparison between the two groups of patients and controls with regard to the expression of the two biomarkers, $\Delta \Delta \mathrm{Ct}$ method was applied. The $\Delta \Delta \mathrm{Ct}$ was calculated to be -0.4 for the CEA mRNA. Next, the $-\Delta \Delta \mathrm{Ct}$ formula was used, which revealed that the number of primary transcripts of this biomarker in patients was averagely 1.32 times the rate in healthy controls.

Also, $\Delta \Delta \mathrm{Ct}$ was found to be -2.78 for MUC1 mRNA; the $-\Delta \Delta \mathrm{Ct}$ formula showed that the number of primary transcripts of this biomarker in patients was averagely 6.87 times the rate in healthy controls (Figure 2 and Table 4).

Comparison of the level of positivity for the CEA mRNA revealed a significant difference between patients and healthy controls $(\mathrm{P}<0.001)$. Comparison of the level of positivity for the MUC1 mRNA revealed a significant difference between patients and healthy controls $(\mathrm{P}<0.011)$ as well. Simultaneous assessment of both biomarkers revealed that in a minimum of 29 patents, expression of one of the two biomarkers was positive, which corresponds to $96.6 \%$ of the cases.

\section{Discussion}

In this study, we evaluated the expression of CEA mRNA and MUC1 mRNA in the peripheral blood of NSCLC patients. Cancer cells are often removed from their primary location and are moved into the bloodstream or other body fluids; thus, they may be noticeable and traceable in peripheral blood and pleural fluid

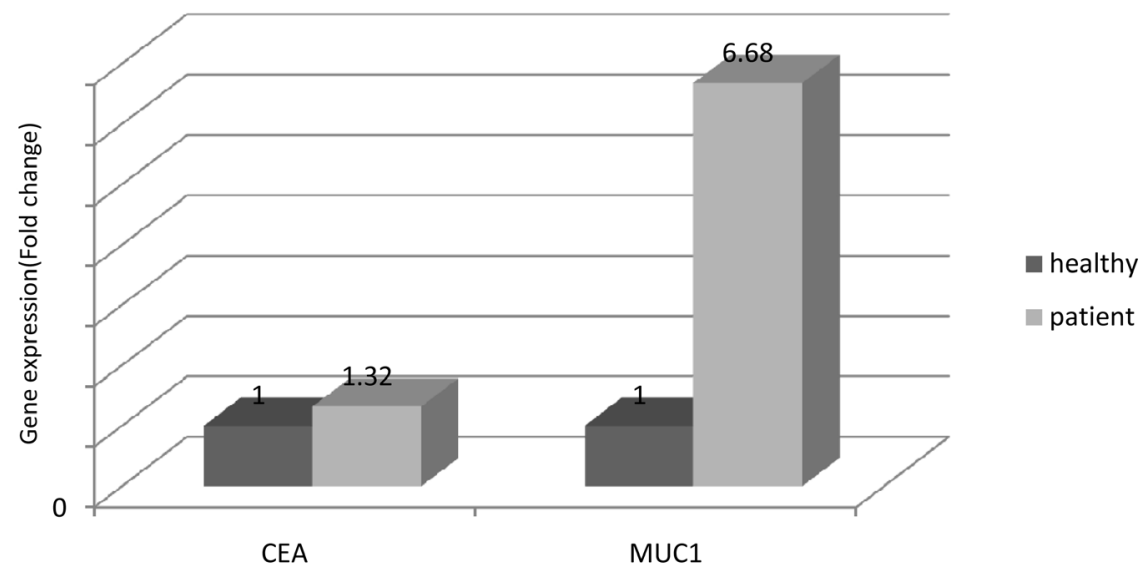

Figure 2. Difference in expression of MUC1 mRNA and CEA mRNA in peripheral blood from NSCLC patients and healthy group.

Table 4. Frequency of NSCLC patients with simultaneous positive expression of both biomarkers.

\begin{tabular}{lrcc}
\hline \multirow{2}{*}{ Patient group } & & \multicolumn{2}{c}{ MUC1mRNA } \\
\cline { 3 - 4 } & & Positive & Negative \\
\hline \multirow{2}{*}{ CEA mRNA } & Positive & 15 & 9 \\
& Negative & 5 & 1 \\
\hline
\end{tabular}


or other body fluids of cancer patients [25] [28]. Researchers have been in search of new innovative methods for earlier detection and diagnosis of lung cancer for earlier onset of treatment and more favorable prognosis [29]. A number of nonsmall cell lung cancer patients who are recognized in primary stages of the disease and undergo surgery die due to tumor recurrence, which shows presence of undetectable metastasis at the time of surgery. These laboratory findings show that the currently used staging system does not have sufficient sensitivity for compartmentalization of cancer patients [30] [31].

Among diagnostic procedures, non-invasive methods such as detection of tumoral biomarkers have been the topic of many investigations for early detection of cancers. Tumoral biomarkers are of several types but mRNA biomarkers are detectable even in very low amounts; they are valuable biomarkers detectable by real-time RT-PCR, with acceptable sensitivity and specificity. The process is via extraction of RNA from the sample, cDNA synthesis by reverse transcription and final conduction of real time RT-PCR [25] [28] [32].

Similar studies have shown that increasing the number of samplings (repeated sampling in several sessions) significantly increases the sensitivity of mRNA biomarkers [29] [30]. This indicates that the odds of detecting markers are lower in a single sampling. Studies on peripheral blood mainly search for tumoral cells to find positive and negative cases by RNA extraction. Obviously, by repeating the sampling for several times the odds of finding tumoral cells increase. Based on this assumption and since repeated sampling from patients was not possible we repeated the test on samples instead of repeating sampling on patients. The tests were performed in triplicate to significantly increase the sensitivity of the markers. This technique has been used in similar previous studies on different types of cancers, and the obtained results have been in line with our findings [12] [25] [31] [33].

In the current study, real time PCR was used for evaluation of MUC1mRNA and CEA mRNA and Showed that MUC1mRNA was a specific marker for detection of non-small cell lung cancer. Also, a significant difference was noted in the expression of CEA mRNA between the patients and controls. In a study Karimi et al. said that LUNX mRNA was particularly expressed in the peripheral blood of non-small cell lung cancer patients. In addition, the expression of CEA mRNA was significantly higher in patients than in healthy controls since 24 out of 30 patients were positive for CEA mRNA [25]. Similarly, the difference in this consideration between patients and controls was statistically significant in this study.

In a study evaluating of CK19 markers and CEA marker was measured by ELISA and real time PCR method and has shown that these markers in patients more than healthy controls [34].

In a similar study on diagnosis of lymph node, micro-metastasis of NSCLC of 43 non-small cell lung cancer tumoral samples $74 \%$ were positive for the MUC1, CK19 and CK7 markers [35]. However, in the current study, this value was $96.6 \%$ for the MUC1 and CEA markers in the peripheral blood of non-small cell lung cancer patients. 
MUC1 mRNA is a cell surface glycoprotein expressed in some cancers with epithelial origin such as non-small cell lung cancer. It induces the expression of genes, which are associated with poor prognosis in NSCLC patients [36]. A previous study showed that the blood level of MUC1 mRNA decreased over the course of treatment but it remained positive in $45.5 \%$ of NSCLC patients at four weeks after treatment [37]. Expression of MUC1 mRNA in the peripheral blood samples taken before and during the course of treatment shows significant potential of this biomarker for prediction of prognosis of non-small cell lung cancer [37].

CEA mRNA and MUC1 mRNA biomarkers can be used for diagnosis of lung cancer with adequately high sensitivity and specificity. However, future investigations with larger sample size are required to find more reliable results. Also, adding other markers is required to find efficient biomarkers enabling more accurate diagnoses.

\section{Conclusion}

CEA mRNA and MUC1 mRNA biomarkers can be used for diagnosis of lung cancer with adequately high sensitivity and specificity. However, future investigations with larger sample size are required to find more reliable results. Also, adding other markers is required to find efficient biomarkers enabling more accurate diagnoses.

\section{Acknowledgements}

We thank Masih Daneshvari Hospital affiliated to Shahid Beheshti University of Medical Sciences, Tehran, Iran Research assistant.

\section{Disclosure Statement}

The authors declare that they have no conflict of interest.

\section{References}

[1] Keith, R.L. and Miller, Y.E. (2013) Lung Cancer Chemoprevention: Current Status and Future Prospects. Nature Reviews Clinical Oncology, 10, 334-343. https://doi.org/10.1038/nrclinonc.2013.64

[2] Gettinger, S.N., Kowanetz, M., Koeppen, H., Wistuba, I.I., Kockx, M., Kadel, E.E., et al. (2015) Molecular, Immune and Histopathological Characterization of NSCLC Based on PDL1 Expression on Tumor and Immune Cells and Association with Response to the Anti-PDL1 Antibody MPDL3280A. American Society of Clinical Oncology, 33, 3015.

[3] Raponi, M., Dossey, L., Jatkoe, T., Wu, X., Chen, G., Fan, H., et al. (2009) MicroRNA Classifiers for Predicting Prognosis of Squamous Cell Lung Cancer. Cancer Research, 69, 5776-5783. https://doi.org/10.1158/0008-5472.CAN-09-0587

[4] Milroy, R. (2007) New American College of Chest Physicians Lung Cancer Guidelines: An Important Addition to the Lung Cancer Guidelines Armamentarium. Chest Journal, 132, 744-746. https://doi.org/10.1378/chest.07-1493 
[5] Thomas, C. and Sweep, C. (2001) Serum Tumor Markers: Past, State of the Art, and Future. The International Journal of Biological Markers, 16, 73-86.

[6] Zheng, H., Chen, Q., Ye, Y. and Huang, W. (2008) mRNA Expression of CK19 and CEA in Peripheral Blood of Patients with Breast Cancer Detected by Real-Time Quantitative PCR. Zhonghua Yi Xue Za Zhi, 88, 2267-2270.

[7] Perez, C.A. and Brady, L.W. (2011) Radiation Oncology: Management Decisions. Lippincott Williams \& Wilkins, Philadelphia.

[8] Franchina, T., Amodeo, V., Bronte, G., Savio, G., Ricciardi, G.R., Picciotto, M., et al. (2014) Circulating miR-22, miR-24 and miR-34a as Novel Predictive Biomarkers to Pemetrexed-Based Chemotherapy in Advanced Non-Small Cell Lung Cancer. Journal of Cellular Physiology, 229, 97-99.

[9] Esquela-Kerscher, A. and Slack, F.J. (2006) Oncomirs-microRNAs with a Role in Cancer. Nature Reviews Cancer, 6, 259-269. https://doi.org/10.1038/nrc1840

[10] Tian, T., Shu, Y., Chen, J., Hu, Z., Xu, L., Jin, G., et al. (2009) A Functional Genetic Variant in microRNA-196a2 Is Associated with Increased Susceptibility of Lung Cancer in Chinese. Cancer Epidemiology and Prevention Biomarkers, 18, 11831187. https://doi.org/10.1158/1055-9965.EPI-08-0814

[11] Calin, G.A., Sevignani, C., Dumitru, C.D., Hyslop, T., Noch, E., Yendamuri, S., et al. (2004) Human microRNA Genes Are Frequently Located at Fragile Sites and Genomic Regions Involved in Cancers. Proceedings of the National academy of Sciences of the United States of America, 101, 2999-3004. https://doi.org/10.1073/pnas.0307323101

[12] Benedíková, A., Srovnal, J., Szkorupa, M., Skalický, P., Chudácek, J., Bohanes, T., et al. (2012) Biomarkers in the Detection of Minimal Systemic Dissemination in Lung Cancer Patients. Rozhledy v Chirurgii: Mesicnik Ceskoslovenske Chirurgicke Spolecnosti, 91, 209-215.

[13] Gerhard, M., Juhl, H., Kalthoff, H., Schreiber, H.W., Wagener, C. and Neumaier, M. (1994) Specific Detection of Carcinoembryonic Antigen-Expressing Tumor Cells in Bone Marrow Aspirates by Polymerase Chain Reaction. Journal of Clinical Oncology, 12, 725-729. https://doi.org/10.1200/JCO.1994.12.4.725

[14] Bahrami, N. , Gholami, M., Jamaati, H.R., Mohamadnia, A., Dargahi, H., Kazempour Dizaji, M., Khosravi, A., Heshmatnia, J., Vahabi, P. and Bahrami, N.A. (2016) Expression of Two Essential mRNA Biomarker in the Peripheral Blood as Possible Biomarkers for Diagnosis of Non-Small Cell Lung Carcinoma. Minerva Pneumologica, 55, 31-36.

[15] Grunnet, M. and Sorensen, J. (2012) Carcinoembryonic antigen (CEA) as Tumor Marker in Lung Cancer. Lung Cancer, 76, 138-143. https://doi.org/10.1016/j.lungcan.2011.11.012

[16] Zhu, G., Liu, D., Wang, X. and Chen, J. (2004) Detection of CK19 and CEA mRNA Expression for the Diagnosis of Peripheral Blood Micrometastases in Patients with Non-Small Cell Lung Cancer. Chinese Journal of Lung Cancer, 7, 226-229.

[17] Li, X., Hu, Y., Zhang, S. and Zheng, S. (2004) Combined Detection of CEA mRNA and CK 19 mRNA in Peripheral Blood Cells of Patients with Lung Cancer. Chinese Journal of Oncology, 26, 382-384.

[18] Peterson, J.A., Scallan, C.D., Ceriani, R.L. and Hamosh, M. (2001) Structural and Functional Aspects of Three Major Glycoproteins of the Human Milk Fat Globule Membrane. Bioactive Components of Human Milk, Springer, New York, 179-187. https://doi.org/10.1007/978-1-4615-1371-1_23 
[19] Hu, X.F., Yang, E., Li, J. and Xing, P.X. (2006) MUC1 Cytoplasmic Tail: A Potential Therapeutic Target for Ovarian Carcinoma. Expert Review of Anticancer Therapy, 6, 1261-1271. https://doi.org/10.1586/14737140.6.8.1261

[20] Leroy, X., Buisine, M.-P., Leteurtre, E., Aubert, S., Buob, D., Porchet, N., et al. (2006) MUC1 EMA, A Key Molecule of Carcinogenesis? Annales de Pathologie, 26, 257-266.

[21] Li, Y. and Cozzi, P. (2007) MUC1 Is a Promising Therapeutic Target for Prostate Cancer Therapy. Current Cancer Drug Targets, 7, 259-271. https://doi.org/10.2174/156800907780618338

[22] Mahanta, S., Fessler, S.P., Park, J. and Bamdad, C. (2008) A Minimal Fragment of MUC1* Mediates Growth of Cancer Cells. PLoS One, 3, e2054. https://doi.org/10.1371/journal.pone.0002054

[23] Hikita, S.T., Kosik, K.S., Clegg, D.O. and Bamdad, C. (2008) MUC1* Mediates the Growth of Human Pluripotent Stem Cells. PloS One, 3, e3312. https://doi.org/10.1371/journal.pone.0003312

[24] Fessler, S.P., Wotkowicz, M.T., Mahanta, S.K. and Bamdad, C. (2009) MUC1* Is a Determinant of Trastuzumab (Herceptin) Resistance in Breast Cancer Cells. Breast Cancer Research and Treatment, 118, 113. https://doi.org/10.1007/s10549-009-0412-3

[25] Karimi, S., Mohamadnia, A., Nadji, S.A., Yadegarazari, R., Khosravi, A., Bahrami, N., et al. (2015) Expression of Two Basic mRNA Biomarkers in Peripheral Blood of Patients with Non-Small Cell Lung Cancer Detected by Real-Time rt-PCR, Individually and Simultaneously. Iranian Biomedical Journal, 19, 17.

[26] Ghadimi, K., Bahrami, N., Fathi, M., Farzanegan, B., Naji, T., Emami, M., et al. (2017) 56, 10.23736/S0026-4954.16.01773-9) D. Diagnostic Value of LunX mRNA and CEA mRNA Expression in Pleural Fluid of Patients with Non-Small Cell Lung Cancer, Minerva Pneumologica.

[27] Karimi, S., Bahrami, N., Sharifi, K., Daustany, M., Baghbani-Arani, F., Kazempour, M., et al. (2017) Investigating Gene Expression Level of MUC1 and CEA in Pleural Fluid of NSCLC Lung Cancer Patients with Real-Time RT-PCR Method. Minerva Pneumologica, 56, 18-24.

[28] Moshref Behzad, N., Bahrami, N., Farzanegan, B., Fathi, M., Zareh Karizi, S. and Mohamadnia, A. (2017) Expression of CK19-mRNA and CEA-mRNA Biomarkers in Pleural Fluid of Patients with Non-Small Cell Lung Cancer. Minerva Pneumologica, 56, 78-83.

[29] Bates, J., Rutherford, R., Divilly, M., Finn, J., Grimes, H., O'Muircheartaigh, I., et al. (1997) Clinical Value of CYFRA 21.1, Carcinoembryonic Antigen, Neurone-Specific Enolase, Tissue Polypeptide Specific Antigen and Tissue Polypeptide Antigen in the Diagnosis of Lung Cancer. European Respiratory Journal, 10, 2535-2538. https://doi.org/10.1183/09031936.97.10112535

[30] Paone, G., De Angelis, G., Munno, R., Pallotta, G., Bigioni, D., Saltini, C., et al. (1995) Discriminant Analysis on Small Cell Lung Cancer and Non-Small Cell Lung Cancer by Means of NSE and CYFRA-21.1. European Respiratory Journal, 8, 11361140. https://doi.org/10.1183/09031936.95.08071136

[31] Iwao, K., Watanabe, T., Fujiwara, Y., Takami, K., Kodama, K., Higashiyama, M., et al. (2001) Isolation of a Novel Human Lung-Specific Gene, LUNX, a Potential Molecular Marker for Detection of Micrometastasis in Non-Small-Cell Lung Cancer. International Journal of Cancer, 91, 433-437. https://doi.org/10.1002/1097-0215(200002)9999:9999<::AID-IJC1059>3.0.CO;2-B 
[32] Jamaati, H., Bahrami, N., Abniki, M., Tabarsi, P., Farzanegan, B., Doroudinia, A., et al. (2016) Real-Time RT-PCR Detection of HCN4 and ADAM8 Genes in Ventilator-Associated Pneumonia Patients Hospitalized in Intensive Care Unit. Journal of Cellular and Molecular Anesthesia, 1, 163-167.

[33] Wallace, M.B., Block, M.I., Gillanders, W., Ravenel, J., Hoffman, B.J., Reed, C.E., et al. (2005) Accurate Molecular Detection of Non-Small Cell Lung Cancer Metastases in Mediastinal Lymph Nodes Sampled by Endoscopic Ultrasound-Guided Needle Aspiration. CHEST Journal, 127, 430-437. https://doi.org/10.1378/chest.127.2.430

[34] Mohamadnia, A., Karimi, S., Yadegar Azari, R., Naji, S.A., Khosravi, A., Bahrami, N., et al. (2016) Expression of CK19 Gene in Patients with Lung Cancer and Its Comparison with Carcinoembryonic Antigen in Peripheral Blood. Journal of Payavard Salamat, 9, 459-468.

[35] Saintigny, P., Coulon, S., Kambouchner, M., Ricci, S., Martinot, E., Danel, C., et al. (2005) Real-Time RT-PCR Detection of CK19, CK7 and MUC1 mRNA for Diagnosis of Lymph Node Micrometastases in Non Small Cell Lung Carcinoma. International Journal of Cancer, 115, 777-782. https://doi.org/10.1002/ijc.20942

[36] Kufe, D.W. (2009) Mucins in Cancer: Function, Prognosis and Therapy. Nature Reviews Cancer, 9, 874-885. https://doi.org/10.1038/nrc2761

[37] Li, J., Hu, Y.-M., Du, Y.-J., Zhu, L.-R., Qian, H., Wu, Y., et al. (2014) Expressions of MUC1 and Vascular Endothelial Growth Factor mRNA in Blood Are Biomarkers for Predicting Efficacy of Gefitinib Treatment in Non-Small Cell Lung Cancer. BMC Cancer, 14, 848. https://doi.org/10.1186/1471-2407-14-848

Submit or recommend next manuscript to SCIRP and we will provide best service for you:

Accepting pre-submission inquiries through Email, Facebook, LinkedIn, Twitter, etc. A wide selection of journals (inclusive of 9 subjects, more than 200 journals)

Providing 24-hour high-quality service

User-friendly online submission system

Fair and swift peer-review system

Efficient typesetting and proofreading procedure

Display of the result of downloads and visits, as well as the number of cited articles

Maximum dissemination of your research work

Submit your manuscript at: http://papersubmission.scirp.org/

Or contact ojcd@scirp.org 